\title{
Paraneoplastic neurologic syndromes
}

\author{
Sedat Şen*, Murat Terzi \\ Department of Neurology, Faculty of Medicine, Ondokuz, Mayıs University, Samsun, Turkey
}

\begin{tabular}{|c|c|}
\hline ARTICLE INFO & ABSTRACT \\
\hline Article History & Paraneoplastic neurologic syndromes (PNS) are manifestations of cancers located outside \\
\hline Received $\quad 27 / 05 / 2013$ & the central nervous system. They appears before the diagnosis of cancer in most of the \\
\hline Accepted $\quad 03 / 08 / 2013$ & $\begin{array}{l}\text { patients. Frequency among all cancer patients is } 0.01 \% \text {. They show close association with } \\
\text { some kinds of cancer. These disorders occure due to stimulation of immune response by }\end{array}$ \\
\hline $\begin{array}{l}\text { * Correspondence to: } \\
\text { Sedat Şen } \\
\text { Department of Neurology, } \\
\text { Faculty of Medicine. }\end{array}$ & $\begin{array}{l}\text { For diagnosis, cancer associated with paraneoplastic syndrome should be detected and } \\
\text { antibody should be demonstrated. Neurologists should be aware of these syndromes so } \\
\text { that appropriate diagnostic and treatment options can be applied sooner. Because the } \\
\text { tumor examination and treatment plan should be made following the diagnosis. }\end{array}$ \\
\hline
\end{tabular}

Ondokuz Mayıs University,

Samsun, Turkey

J. Exp.Clin. Med., 2013; 30: 209-213

e-mail: sedatsen83@hotmail.com

\author{
Keywords: \\ Cancer \\ Diagnosis \\ Paraneoplastic syndromes \\ Pathophysiology \\ Treatment
}

(C) 2013 OMU

\section{Introduction}

Paraneoplastic neurologic syndromes (PNS) are manifestations of cancers which are located outside the central nervous system. They appear before the diagnosis of cancer in most of patients. Identification of these disorders is very important as it leads to diagnosis and treatment of cancer subsequently. PNS are divided into two groups as classical and non-classical. Classical PNS are associated with cancer more than non-classical PNS. Non-classical PNS are rather observed in cases without cancer. PNS can also be divided into two groups as per the involvement of the central and peripheral nervous system (Table 1) (Bradley, 2008; Tüzün, 2010).

\section{Epidemiology}

PNS are rare disorders in cancer patients. Frequency in all cancer patients is $0.01 \%$ (Darnell and Posner, 2003). Women/ men ratio is approximately $3: 1$. It is usually observed beyond mid-life. They show a closer association with some kinds of cancer. They have a more frequent association especially with hematologic diseases such as small cell lung cancer (SCLC), thymoma, and monoclonal gammopathy. Other can- cer types associated with PNS include breast, gynecological cancers such as ovarian and Hodgkin's, non-Hodgkin's lymphoma, testicular cancer and neuroblastoma (Toothaker and Rubin, 2009). Furthermore, development of PNS is possible in almost all neoplasms (Bataller and Dalmau, 2003).

\section{Pathogenesis}

A widely accepted opinion is that these disorders occur due to stimulation of immune response by some proteins which are formed by a tumor, against both the tumor and the nervous system (Tüzün, 2010). Cytotoxic T-cell responses have a very important role in pathogenesis of PNS (Bradley, 2008). T-cells are responsible for both of the antibody-mediated processes (Albert et al., 1998). Lymphocytic pleocytosis and oligoclonal band positivity may be observed in BOS analysis (Armstrong et al., 2005).

PNS are formed by antibodies developed against the intracellular antigen or neuronal surface antigen. In limbic encephalitis, there are antibodies for both regions. Anti Hu, anti Yo, anti Ri, anti Ma2, Cv2/CRMP5 are antibodies associated with intracellular antigen, whereas the VGKC complex 
Table 1. Paraneoplastic neurologic disorders

\section{Classical syndromes}

Subacute cerebellar degeneration

Limbic encephalitis

Encephalomyelitis

Opsoclonus myoclonus
Non-classical syndromes

Brainstem encephalitis

Optical neuritis

Stiff-man syndrome

Myelitis

Necrotizing myelopathy

Motor neuron disease

Retinopathy

Myasthenia gravis

Subacute motor neuropathy

Subacute-chronic sensorimotor neuropathy

Guillain-Barré syndrome

Vasculitic neuropathy

Mononeuritis multiplex

Brachial neuritis

Neuromyotonia

Polymyositis

Inflammatory myopathy antigens (LGI1, CASPAR2), NMDAR, AMPAR, GABAR, GlyR, VGCC-Ab, mGluR1, mGluR5 are antibodies associated with neuronal surface antigen. Cellular immunity plays a major role in diseases associated with intracellular antigen. Location of antigen may change the treatment response of disease (Honnorat and Antoine, 2007; Graus and Dalmau, 2007; Tüzün and Dalmau, 2007; Toothaker and Rubin, 2009; Sadeghian and Vernigo, 2010; Tüzün, 2010). Anti-neuronal antibodies and associated cancer types are provided in Table 2.

\begin{tabular}{ll}
\multicolumn{2}{l}{ Table 2. Anti-neuronal antibody } \\
\hline Anti-neuronal antibody & Cancer type \\
\hline Anti-Hu & Lung (most common SCLC), prostate, GIS \\
Anti-Yo & Ovary, breast \\
Anti-Ri & Ovary, breast \\
Anti-Ma2 & Testicle, lung \\
Anti-amphiphysin & SCLC, breast \\
Anti-Tr & Hodgkin's lymphoma \\
Anti-NMDAR & Ovary (teratoma) \\
Anti-mGluR1 & Hodgkin's lymphoma \\
VC2/CRMP5 & Thymoma, SCLC \\
\hline
\end{tabular}

\section{Diagnosis}

For diagnosis, the cancer associated with syndrome should be detected and antibody should be demonstrated. Neurological symptoms appear before the diagnosis of underlying tumor in approximately $60 \%$ of the patients with PNS (Bradley, 2008). A number of diagnostic criteria have been established for diagnosis of PNS (Honnorat and Antoine, 2007; Graus and Dalmau, 2007; Toothaker and Rubin, 2009).

\section{Absolute PNS criteria}

1. Detection of classical neurologic syndrome (encephalomyelitis, limbic encephalitis, subacute cerebellar degeneration, sensory neuropathy, opsoclonus myoclonus, Lambert-Eaton myasthenic syndrome and dermatomyositis) and associated cancer (within 5 years of diagnosis of syndrome).

2. Healing or pronounced recovery in a non-classical syndrome following the cancer treatment.

3. Detection of anti-neuronal antibody together with the non-classical syndrome and cancer.

4. Detection of a well-characterized anti-neuronal antibody (anti Ri, anti $\mathrm{Hu}$, anti Yo, anti Ma2, anti CV2 and anti-amphiphysin) together with the neurologic syndrome in the absence of accompanied cancer.

\section{Possible PNS criteria}

Undetectable underlying cancer and antibody but high risk of underlying tumor in a patient with classical neurologic syndrome. Detection of anti-neuronal antibody despite the absence of neurologic syndrome or cancer. Presence of classical neurologic syndrome and cancer (within two years of diagnosis of syndrome) in a patient without anti-neuronal antibodies.

\section{Paraneoplastic Syndromes}

\section{Limbic encephalitis}

Characteristic features of limbic encephalitis are subacute confusion and impairment of short-term memory (Tüzün and Dalmau, 2007). Manifestation is usually accompanied by epileptic seizures. Depression, psychosis and sleep disturbances are also observed. Most commonly detected cancer type is SCLC with the rate of approximately 50\%. Furthermore, testicular cancer and breast cancers are observed with the rates of $20 \%$ and $8 \%$, respectively (Gultekin et al., 2000). Although rarely, ovarian teratoma, thymoma and Hodgkin's disease may be observed. Prognosis is usually poor if limbic encephalitis is developed due to an underlying cancer (Tüzün and Dalmau, 2007). In patients with limbic encephalitis developed due to intracellular antigens such as $\mathrm{Hu}, \mathrm{Ma} 2, \mathrm{CV} 2$ and amphiphysin, usually an underlying cancer exists and prognosis is poor (Tüzün, 2010; Dalmau et al., 2004). In cases with limbic encephalitis due to the cell membrane antigens such as N-Methyl-D-aspartate-type glutamate receptor (NMDAR) and voltage-gated potassium channels (VGPC), usually no underlying cancer is observed and treatment responses are good (Tüzün and Dalmau, 2007). Anti Hu is the most commonly detected antibody (in $60 \%$ of the cases). Type of underlying cancer is SCLC in $94 \%$ of these patients (Toothaker and Rubin, 2009). T2 and flair hyperintense lesions are observed in one or both of the medial temporal lobe structures in $80 \%$ of patients with limbic encephalitis. Even if magnetic resonance imaging (MRI) is normal, positron emission tomography (PET) may show involvement in these regions (Ances et al., 2005; Bataller et al., 2007). Lymphocytic pleocytosis, increased protein, and oligoclonal band positivity may be observed in BOS analysis. Epileptic discharges may be observed in temporal regions in electroencephalography (EEG) (Toothaker and Rubin, 2009). 


\section{Subacute cerebellar degeneration}

Subacute cerebellar degeneration is a pancerebellar syndrome resulting from the common and severe lost of the cerebellar purkinje cells. It is associated with gynecologic, breast cancers, SCLC and Hodgkin's lymphoma (Graus and Dalmau, 2007). Cerebellar symptoms such as ataxia, dysarthria and nystagmus are followed by gait and posture disorders, and the patients become non-functional in daily activities within weeks (Hammack et al., 1992; Peterson et al., 1992). Initial MRI findings of the patients may be normal. In late stage, cerebellar atrophy and inflammation findings in BOS are developed (Graus and Dalmau, 2007). These are most commonly occurred associated with anti-Yo. Furthermore, antibodies such as Tr, Hu, Ma2, and Ri may be detected. Treatment response is usually poor; however, a response may be obtained with early interventions of aggressive immunotherapy and cancer therapy. There are also publications indicating that intravenous immunoglobulin (IVIG) is beneficial (Widdess-Walsh et al., 2003; Phuphanich and Brock, 2007).

\section{Opsoclonus-myoclonus}

There are involuntarily, arrhythmic, high-amplitude, versatile saccadic movements and myoclonic jerks. Furthermore, cerebellar ataxia may be observed. It is observed in association with SCLC, breast and gynecologic cancers in adults and in cases with neuroblastoma in children. Its association with neuroblastoma is $2-3 \%$. Neuroblastoma is accompanied by $40 \%$ in case of pediatric opsoclonus-myoclonus. In this case, findings such as hypotonia, mental retardation may be observed (Rudnick et al., 2001; Tate et al., 2005). The brain MRI is usually normal. Mild pleocytosis may be observed in BOS. Anti-Ri antibody accompanied with breast and gynecologic cancers was detected in adult cases, while no antibody was detected in pediatric group (Wong, 2007).

It is one of the PNS showing the best response to treatment. IVIG, corticosteroids and plasmapheresis may be usefull in the treatment. Treatment possibility is less in children when compared to adults (Bataller et al., 2001). Rituximab therapy may be tried in suitable patients (Pranzatelli et al., 2006).

\section{Encephalomyelitis}

Paraneoplastic encephalomyletis is characterized by neuronal loss and inflammation in multiple regions of nervous system (Graus et al., 2001). Involved regions include hippocampus, cerebellum, brain stem and medulla spinalis. Dorsal root ganglion may be involved in sympathetic and parasympathetic ganglia. Symptoms are occurred in patients as per the situations of affected neurons in these involved regions. Myelitis, brainstem encephalitis, cerebellar degeneration, sensory neuropathy, orthostatic hypotension, and arrhythmia may develop (Antonie et al., 1993; Graus et al., 2001). The most commonly detected conditions are SCLC and anti-Hu. Furthermore, antibodies of CV2, amphiphysin and Ri may be detected (Graus and Dalmau, 2007). Lymphocytic pleocytosis, increased protein, and oligoclonal band positivity are likely to be observed in BOS analysis of patients.

\section{Peripheral neuropathy}

This is a mixed axonal/demyelinating disorder (Camdessanche et al., 2002) and it occurs in result of the damage in all peripheral nerves of axonal, motor, sensory and autonomous by effect of cancer. Damage generally occurs due to direct spread effect of cancer, radiotherapy, chemotherapy, nutritional deficiency and leptomeningeal metastases (Antoine and Camdessanche, 2007). The most commonly seen form of paraneoplastic peripheral neuropathy is subacute sensory neuropathy. It is observed in patients with anti-Hu positive SCLC (Molinuevo et al., 1998). As with other paraneoplastic disorders, pleocytosis, increased protein, and oligoclonal band positivity may be observed in BOS also in sensory neuropathy (Antoine and Camdessanche, 2007). Cases with anti CV2 positive SCLC and thymoma are usually accompanied by monoclonal gammopathy, multiple myeloma, and sensory neuropathy in Waldenstöm macroglobulinemia (Antoine et al., 2001; Levine et al., 2006).

Paraneoplastic autonomous neuropathy is usually observed in patients with anti-Hu positive SCLC. Manifestations usually accompanied by limbic encephalitis and sensory neuropathy. Furthermore, findings such as pseudo-obstruction, orthostatic hypotension, bladder dysfunction, and arrhythmia may also be observed (Dalmau et al., 1992).

\section{Retinopathy}

There are three types of retinopathy associated with cancer. Cancer associated retinopathy (CAR), melanoma associated retinopathy (MAR) and paraneoplastic optic neuropathy (Damek, 2005). Vision loss without pain, photosensitivity and scotoma are observed in patients with CAR. The most commonly detected antibody that shows SCLC is recoverin in patients with CAR (Bataller and Dalmau, 2004).

No defects in visual acuity are observed in patients with MAR, however, sudden night blindness is observed (Damek, 2005). Several MAR-like syndromes are associated with colon cancer. Otherwise, it is almost always associated with melanoma (Jacobson and Adamus, 2001). Paraneoplastic optic neuropathy is rarely seen alone. It is usually observed with encephalomyletis and SCLC (Toothaker and Rubin, 2009).

\section{Lambert-Eaton myasthenic syndrome (LEMS)}

An autoimmune disease of neuromuscular junction characterized by muscle weakness and autonomous dysfunction. LEMS is paraneoplastic in $60 \%$ and highly associated with SCLC. Less often, it is associated with lymphoma. 3 percent of the SCLC patients LEMS develops (O'Neill et al., 1988; Newsom-Davis, 2004). P/Q-type voltage-gated calcium channels (VGCC) channel antibodies are responsible for the development of disease. Compound muscle action potentials (CMAP) of low amplitude and normal latency at low frequencies such as $1-5 \mathrm{~Hz}$ are obtained with the consecutive nerve stimulations performed electrophysiologically to the patient. CMAP with amplitude increased by $100 \%$ or more is obtained with the consecutive nerve stimulation following exercise. This is due to increase in release of acetylcholine by the calcium accumulated in the nerve terminal during exercise (Mareska and Gutmann, 2004). Treatment of paraneoplastic cases is targeted the underlying tumor, whereas in antibody-mediated cases without underlying malignancy, IVIG and plasma exchange may be used. There are publications indicating that 3,4-diaminopyridine may be beneficial (Chalk et al., 1990; Sanders et al., 2000). 


\section{Dermatomyositis, polymyositis}

Dermatomyositis is a manifestation where characteristic skin lesions composed of periungual telangiectasia, photosensitivity, heliotrope rash and erythematous scaly plaques are accompanied by idiopathic inflammatory myopathy. Predominant proximal symmetric myopathy is observed and it has a slow progression. Disease is occurred as paraneoplastic with a possibility of $30 \%$. In this case, gynecologic, lung, pancreas, colon, stomach cancers and Non-Hodgkin lymphoma may underlie (Sigurgeirsson et al., 1992; Hill et al., 2001). Antibodies are usually undetectable in cases with underlying tumor. Priority in paraneoplastic cases is the treatment of tumor. Otherwise, corticosteroids, azathioprine, IVIG and immunosuppressives may be used in autoimmune and paraneoplastic patients (Honnorat and Antoine, 2007).

The form of muscle weakness is as dermatomyositis in polymyositis as well. No skin findings are observed. Malignancy rate is lower by about $15-18 \%$. Lung, bladder and Non-Hodgkin lymphoma may exist (Amoura et al., 2005; Targoff et al., 2006).

\section{Stiff-Person syndrome}

Stiff-Person syndrome is characterized by muscle stiffness developed in months, which is particularly prominent in back and leg muscles. Widespread muscle pains and painful muscle spasms are observed (Rosenfeld and Dalmau, 2010). Continuous motor activity is observed in EMG. It occurs with autoimmune mechanisms in $70 \%$ of the patients and contains anti-GAD antibody (Honnorat and Antoine, 2007). Patients developed it as paraneoplastic are usually women with anti-amphiphysin positive breast cancer (Folli et al., 1993; Petzold et al., 2004). Treatment primarily targets the underlying disease, however corticosteroids, IVIG, diazepam and GABAergic agents may also be used (Rosenfeld and Dalmau, 2010).

\section{REFERENCES}

Albert, M.L., Darnell, J.C., Bender, A., Francisco, L.M., Bhardwaj, N., Darnell, R.B., 1998. Tumor-specific killer cells in paraneoplastic cerebellar degeneration. Nature Med. 4, 1321-1324.

Amoura, Z., Duhaut, P., Huong, D.L., Wechsler, B., Costedoat-Chalumeau, N., Francès, C., Cacoub, P., Papo, T., Cormont, S., Touitou, Y., Grenier, P., Valeyre, D., Piette, J.C., 2005. Tumor antigen markers for the detection of solid cancers in inflammatory myopathies. Cancer Epidemiol Biomarkers Prev. 14, 1279-1282.

Ances, B.M., Vitaliani, R., Taylor, R.A., Liebeskind, D.S., Voloschin, A., Houghton, D.J., Galetta, S.L., Dichter, M., Alavi, A., Rosenfeld, M.R., Dalmau, J., 2005. Treatment-responsive limbic encephalitis identified by neuropil antibodies: MRI and PET correlates. Brain. 128, 1764-1777.

Antoine, J.C., Camdessanche, J.P., 2007. Peripheral nervous system involvement in patients with cancer. Lancet Neurol. 6, 75 - 86.

Antoine, J.C., Honnorat, J., Camdessanché, J.P., Magistris, M., Absi, L., Mosnier, J.F., Petiot, P., Kopp, N., Michel, D., 2001 . Paraneoplastic anti-CV2 antibodies react with peripheral nerve and are associated with a mixed axonal and demyelinating peripheral neuropathy. Ann Neurol. 49, 214-221.

Antoine, J.C., Honnorat, J., Vocanson, C., Koenig, F., Aguera, M., Belin, M.F., Michel, D., 1993. Posterior uveitis, paraneoplastic encephalomyelitis and auto-antibodies reacting with developmental protein of brain and retina. J. Neurol. Sci. 117, 215-223.

Armstrong, M.B., Robertson, P.L., Castle, V.P., 2005. Delayed, recurrent opsoclonus-myoclonus syndrome responding to plasmapheresis. Pediatric Neurol. 33, 365- 367.

Bataller, L., Dalmau, J., 2003. Paraneoplastic neurologic syndromes: Approaches to diagnosis and treatment. Sem. In. Neurol. 23 , $215-224$.

Bataller, L., Dalmau, J., 2004. Neuro-ophthalmology and paraneoplastic syndromes. Curr. Opin. Neurol. 17, $3-8$.

Bataller, L., Graus, F., Saiz, A., Vilchez, J.J., Spanish Opsoclonus-Myoclonus Study Group, 2001. Clinical outcome in adult onset idiopathic or paraneoplastic opsoclonus-myoclonus. Brain. 124, 437- 443.

Bataller, L., Kleopa, K.A., Wu, G.F., Rossi, J.E., Rosenfeld, M.R., Dalmau, J., 2007. Autoimmune limbic encephalitis in 39 patients: Immunophenotypes and outcomes. J. Neurol. Neurosurg. Psychiatry. 78, 381- 385.

Bradley, W.G., 2008, Neurology in Clinical Practice, fifth edition, Part 3, Philadelphia. pp. 1405-1415.

Camdessanche, J.P., Antoine, J.C., Honnorat, J., Vial, C., Petiot, P., Convers, P., Michel, D., 2002. Paraneoplastic peripheral neuropathy associated with anti-Hu antibodies. Brain. 125, 166-175.

Chalk, C.H., Murray, N.M., Newsom-Davis, J., O’Neill, J.H., Spiro, S.G., 1990. Response of Lambert-Eaton myasthenic syndrome to treatment of associated small-cell lung carcinoma. Neurology. 40, 1552-1556.

\begin{abstract}
A progressive, degenerative disease which involves upper or lower neurons or both. Patients show the lower motor neuand upper motor neuron findings such as extensor plantar rein amyotrophic lateral sclerosis (ALS) is 50\% (Rowland and

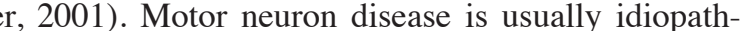
cancer (Kurtzke and Beebe, 1980; Chio et al., 1988). Only a in motor neuron disease (Stich et al., 2007). However, there are patients with motor neuron disease that have been report-
\end{abstract}

Treatment protocol for patients with paraneoplastic neuwhich is applicable for all diseases, is to treat the underlying of patients are needed to determine the treatment protocols

As paraneoplastic syndromes are seen rarely, it is hard to dirological signs are observed before diagnosis of tumor. Anti-neuronal antibodies are very important in detecting these mine these diseases because the tumor examination and treatment plan should be made following the diagnosis. tre 
Chiò, A., Brignolio, F., Meineri, P., Rosso, M.G., Tribolo, A., Schiffer, D., 1988. Motor neuron disease and malignancies: Results of a population-based study. J. Neurol. 235, 374 -375.

Dalmau, J., Graus, F., Rosenblum, M.K., Posner, J.B., 1992. Anti-Hu associated paraneoplastic encephalomyelitis/sensory neuronopathy. A clinical study of 71 patients. Medicine (Baltimore). 71, 59-72.

Dalmau, J., Graus, F., Villarejo, A., Posner, J.B., Blumenthal, D., Thiessen, B., Saiz, A., Meneses, P., Rosenfeld, M.R., 2004. Clinical analysis of anti-Ma2 associated encephalitis. Brain. 127, 1831-1844.

Damek, D.M., 2005. Paraneoplastic retinopathy/optic neuropathy. Curr. Treat. Options Neurol. 7, 57- 67.

Darnell, R.B., Posner, J.B., 2003. Paraneoplastic syndromes involving the nervous system. N. Eng. J. Med. 349, $1543-1554$.

Folli, F., Solimena, M., Cofiell, R., Austoni, M., Tallini, G., Fassetta, G., Bates, D., Cartlidge, N., Bottazzo, G.F., Piccolo, G., Camilli, P.D., 1993. Autoantibodies to a 128-kd synaptic protein in three women with the stiff-man syndrome and breast cancer. N. Engl. J. Med. 328, 546-551 .

Graus, F., Dalmau, J., 2007. Paraneoplastic neurological syndromes: Diagnosis and treatment. Curr. Opin. Neurol. 20, $732-737$.

Graus, F., Dalmau, J., 2012. Paraneoplastic neurological syndromes: Diagnosis and treatment. Curr. Opin. Neurol. 25, $795-801$.

Graus, F., Keime-Guibert, F., Reñe, R., Benyahia, B., Ribalta, T., Ascaso, C., Escaramis, G., Delattre, J.Y., 2001. Anti-Hu-associated paraneoplastic encephalomyelitis: Analysis of 200 patients. Brain. 124, 1138-1148.

Gultekin, S.H., Rosenfeld, M.R., Voltz, R., Eichen, J., Posner, J.B., Dalmau, J., 2000. Paraneoplastic limbic encephalitis: Neurological symptoms, immunological findings and tumour association in 50 patients. Brain. 123, 1481-1494.

Hammack, J., Kotanides, H., Rosenblum, M.K., Posner, J.B., 1992. Paraneoplastic cerebellar degeneration. II. Clinical and immunologic findings in 21 patients with Hodgkin's disease. Neurol. 42, 1938-1943.

Hill, C.L., Zhang, Y., Sigurgeirsson, B., Pukkala, E., Mellemkjaer, L., Airio, A., Evans, S., Felson, D., 2001. Frequency of specific cancer types in dermatomyositis and polymyositis: A population-based study. Lancet. 357, 96-100.

Honnorat, J., Antoine, J.C., 2007. Paraneoplastic neurological syndromes. Orphanet. J. Rare Dis. 2, 22.

Jacobson, D.M., Adamus, G., 2001. Retinal anti-bipolar cell antibodies in a patient with paraneoplastic retinopathy and colon cancer. Am. J. Ophthalmol. 131, 806-808.

Khwaja, S., Sripathi, N., Ahmad, B.K., Lennon, V.A., 1998. Paraneoplastic motor neuron disease with type 1 purkinje cell antibodies. Muscle Nerve. 21,943-945.

Kurtzke, J.F., Beebe, G.W., 1980. Epidemiology of amyotrophic lateral sclerosis: 1. a case control comparison based on ALS deaths. Neurology. $30,453-462$.

Levine, T., Pestronk, A., Florence, J., Al-Lozi, M.T., Lopate, G., Miller, T., Ramneantu, I., Waheed, W., Stambuk, M., Stone, M.J., Choksi, R., 2006. Peripheral neuropathies in Waldenström's macroglobulinaemia. J. Neurol. Neurosurg. Psychiatry. 77, 224-228.

Mareska, M., Gutmann, L., 2004. Lambert-Eaton myasthenic syndrome. Semin. Neurol. 24, 149 -153.

Molinuevo, J.L., Graus, F., Serrano, C., Reñe, R., Guerrero, A., Illa, I., 1998. Utility of anti-Hu antibodies in the diagnosis of paraneoplastic sensory neuropathy. Ann Neurol. 44, 976-980.

Newsom-Davis, J., 2004. Lambert-Eaton myasthenic syndrome. Rev. Neurol. (Paris). 160,177-180.

O’Neill, J.H., Murray, N.M., Newsom-Davis, J., 1988. The Lambert-Eaton myasthenic syndrome. A review of 50 cases. Brain. 111, 577-596.

Peterson, K., Rosenblum, M.K., Kotanides, H., Posner, J.B., 1992. Paraneoplastic cerebellar degeneration I. A clinical analysis of 55 anti-Yo antibody-positive patients. Neurol. 42, 1931-1937.

Petzold, G.C., Marcucci, M., Butler, M.H., van Landeghem, F.K., Einhaupl, K.M., Solimena, M., Valdueza, J.M., De Camilli, P., 2004. Rhabdomyolysis and paraneoplastic stiff-man syndrome with amphiphysin autoimmunity. Ann Neurol. 55, 286-290.

Phuphanich, S., Brock, C., 2007. Neurologic improvement after high-dose intravenous immunoglobulin therapy in patients with paraneoplastic cerebellar degeneration associated with anti-Purkinje cell antibody. J. Neurooncol. 81, 67- 69.

Pranzatelli, M.R., Tate, E.D., Travelstead, A.L., Barbosa, J., Bergamini, R.A., Civitello, L., Franz, D.N., Greffe, B.S., Hanson, R.D., Hurwitz, C.A., Kalinyak, K.A., Kelfer, H., Khakoo, Y., Mantovani, J.F., Nicholson, S.H., Sanders, J.M., Wnegwe, S., 2006. Rituximab (anti-CD20) adjunctive therapy for opsoclonus-myoclonus syndrome. J. Pediatr. Hematol. Oncol. 28, 585-593.

Rosenfeld, M.R., Dalmau, J., 2010. Update on paraneoplastic neurologic disorders. The Oncologist. 15, 603-617.

Rowland, L.P., Shceider, N.A., 2001. Amyotrophic lateral sclerosis. N. Engl. J. Med. 344, $1688-1700$.

Rudnick, E., Khakoo, Y., Antunes, N.L., Seeger, R.C., Brodeur, G.M., Shimada, H., Gerbing, R.B., Stram, D.O., Matthay, K.K., 2001. Opsoclonus-myoclonus-ataxia syndrome in neuroblastoma: Clinical outcome and antineural antibodies-a report from the Children's Cancer Group study. Med. Pediatr. Oncol. 36, 612-622.

Sadeghian, H., Vernino, S., 2010. Progress in the management of paraneoplastic neurological disorders. Ther. Adv. Neurol. Disord. 3 , $43-52$.

Sanders, D.B., Massey, J.M., Sanders, L.L., Edwards, L.J., 2000. A randomized trial of 3,4- diaminopyridine in Lambert-Eaton myasthenic syndrome. Neurology. 54, 603-607.

Sigurgeirsson, B., Lindelöf, B., Edhag, O., Allander, E., 1992. Risk of cancer in patients with dermatomyositis or polymyositis. N. Engl. J. Med. 326, 363-367.

Stich, O., Kleer, B., Rauer, S., 2007. Absence of paraneoplastic antineuronal antibodies in sera of 145 patients with motor neuron disease. J Neurol Neurosurg Psychiatry. 78, 883-885.

Targoff, I.N., Mamyrova, G., Trieu, E.P., Perurena, O., Koneru, B., O’Hanlon, T.P., Miller, F.W., Rider, L.G., 2006. Childhood Myositis Heterogeneity Study Group; International Myositis Collaborative Study Group A novel autoantibody to a 155-kd protein is associated with dermatomyositis. Arthritis. Rheum. 54, 3682-3689.

Tate, E.D., Allison, T.J., Pranzatelli, M.R., Verhulst, S.J., 2005. Neuroepidemiologic trends in 105 US cases of pediatric opsoclonus-myoclonus syndrome. J. Pediatr. Oncol. Nurs. 22, 8-19.

Toothaker, T.B., Rubin, M., 2009. Paraneoplastic neurological syndromes: A review. Neurologist. 15, 21-33.

Tüzün E, Dalmau J., 2007. Limbic encephalitis and variants: Classification, diagnosis and treatment. Neurologist. 13, $261-271$.

Tüzün, E., 2010. Neurological involvement in navigating the paraneoplastic syndromes. Klinik Gelisim. 23.1, 71-77.

Verma, A., Berger, J.R., Snodgrass, S., Petito, C., 1996. Motor neuron disease: A paraneoplastic process associated with anti-Hu antibody and small-cell lung carcinoma. Ann Neurol. 40, 112-116.

Widdess-Walsh, P., Tavee, J.O., Schuele, S., Stevens, G.H., 2003. Response to intravenous immunoglobulin in anti-Yo associated paraneoplastic cerebellar degeneration: Case report and review of the literature. J. Neurooncol. 63, 187-190.

Wong, A., 2007. An update on opsoclonus. Curr. Opin. Neurol. 20, 25-31. 